\title{
A IMPORTÂNCIA DE UMA OUVIDORIA PÚBLICA PARA A GESTÃO DE UM ESTABELECIMENTO DE SAÚDE
}

\author{
Francisco lonário Nunes de Sousa ${ }^{1}$
}

\begin{abstract}
Resumo
A proposta desta pesquisa tem como objeto identificar em que perspectiva uma Ouvidoria Pública da saúde contribui como instrumento de gestão da Administração Pública. Para tanto, torna-se necessário entender a origem e a evolução histórica da Ouvidoria. Nesse sentido, pretende-se perceber quais as informações recebidas por uma Ouvidoria e de que forma esses registros são utilizados para gerar resultados satisfatórios para a sociedade. Dessa forma, busca-se contribuir para a sistematização teórica a respeito do tema proposto e uma reflexão aprofundada no que tange à garantia de direitos e à participação social, algo que se constitui em desafio para estabelecimentos de saúde, assistência, entre outros. O estudo pretende ampliar o arcabouço teórico em relação a uma Ouvidoria Pública como ferramenta que auxilia o gestor na tomada de decisão e na melhoria das rotinas de trabalho de um estabelecimento público.
\end{abstract}

Palavras-chave: Ouvidoria. Cidadania. Políticas públicas. Gestão.

1 Especialista em Gestão Pública. Especialista em Gestão em Saúde. Formado em Gestão Hospitalar. Instituto de Saúde Hospitalar (ISGH). Fortaleza, Ceará. (yorran500@yahoo.com.br.) 


\section{Abstract}

The purpose of this research is to identify the perspective in which a Public Health Ombudsman contributes as a management tool for public administration. Therefore, it is necessary to understand the origin and the historical evolution of the Ombudsman's Office. In this sense, it is intended to perceive the information received by an Ombudsman and in what form these records are used to generate satisfactory results to society. In this way, we seek to contribute to the theoretical systematization regarding the proposed theme and an in-depth reflection regarding the guarantee of rights and social participation, something that constitutes a challenge for health care establishments, assistance, among others. The study intends to broaden the theoretical framework in relation to a Public Ombudsman's Office as a management tool that assists the manager in the decision-making process and in the improvement of the work routines of a public establishment.

Keywords: Ombudsman. Citizenship. Public policies. Management. 


\section{INTRODUÇÃO}

O poder emana do povo não somente pela via da democracia representativa (escolha dos representantes políticos), mas também pela participação direta nas questões públicas ao falar em democracia, e, no contexto do SUS, em cidadania enquanto direito a saúde, é preciso ver além do acesso à assistência de saúde. Esse conceito de cidadania pode ser exercido por ações de efetivo controle das decisões da saúde pública. A todo cidadão é garantido expressar a democracia por meio de formas concretas e diretas de participação em favor dos seus direitos. A gestão do SUS pode e deve ser realizada considerando o olhar da sociedade.

Todo poder emana do povo, que o exerce por meio de representantes eleitos ou diretamente, nos termos desta Constituição. (Parágrafo Único do Artigo $1^{\circ}$ da Constituição Federal de 1988)

Atendendo a essa necessidade, foi criado, em 09 de junho de 2013, por meio do Decreto $\mathrm{n}^{\circ}$ 4.726, o departamento de Ouvidoria-Geral do SUS, que compõe a Secretaria de Gestão Estratégica e Participativa (SGEP) do Ministério da Saúde. Desde então tem sido um meio transformador de estímulo à participação social.

A motivação para estudar a importância de uma Ouvidoria como instrumento de políticas públicas e controle social surgiu a partir da vivência enquanto Ouvidor nas Unidades de Pronto Atendimento (UPAs), especialmente na Assistência de Alta Complexidade do município de Fortaleza (CE). Há três anos, tenho a oportunidade de vivenciar como Ouvidor a difícil missão de mediar conflitos, gerenciar informações e manifestações dos usuários do sistema de saúde da capital cearense, que se apresentam, entre outros fatores, ligados a direitos garantidos pela Constituição. Nesse local de trabalho é possível observar que as informações estão ligadas às necessidades e exigências do usuário, atribuindo a esse o papel de agente de mudança. A Ouvidoria das Unidades de Pronto Atendimento (UPAs) da cidade de Fortaleza tem uma demanda anual acima de 1.400 manifestações, incluindo reclamações, elogios, denúncias, solicitações de informação e sugestões. A observação desses dados fez surgir a reflexão a respeito da importância de uma Ouvidoria como instrumento de gestão.

O objetivo da pesquisa foi identificar em que perspectiva uma Ouvidoria Pública da saúde contribui como instrumento de gestão. Ao adotar as concepções propostas, aprofunda-se a Ouvidoria como um espaço de interação e conhecimento, onde o cidadão conversa a fim de alcançar seu objetivo, na espera de uma mudança e da realimentação de sua iniciativa de interagir, contribuindo, com saberes novos, para a organização. Considerando esse modelo e refletindo a Ouvidoria como canal ascendente de comunicação, é fundamental discuti-la como possibilidade real de instigar relacionamentos com o público e como processo necessariamente unido às pessoas.

\section{DESENVOLVIMENTO}

Ao longo dos séculos XVI a XIX ocorre um movimento crescente: a inserção da figura do Om- 
budsman em vários países do mundo, com a função de representar a escuta do cidadão nas organizações. Ombudsman é uma expressão de origem sueca que significa "representante do cidadão". A palavra é formada pela união de "ombuds" (representante) e "man" (homem). O termo surgiu em 1809, nos países escandinavos, para designar um Ouvidor-Geral do Parlamento, responsável em mediar e tentar solucionar as reclamações da população feitas ao governo. Hoje em dia, o Ombudsman se transformou em uma profissão presente em quase todas as grandes e médias empresas, sejam públicas ou privadas. A função do búds, como também é conhecido, é a de enxergar os problemas e pontos negativos de determinada empresa ou instituição, a partir da ótica do consumidor/ cidadão, e tentar solucionar as crises de maneira imparcial. Com isso, a Ouvidoria tornar-se um instrumento de transparência e permeabilidade à demanda externa, em observância à crescente densidade organizacional da sociedade civil.

A Ouvidoria pode ser considerada uma função do planejamento estratégico, uma vez que se apresenta como instrumento de transformação permanente - fator que permite projetar o futuro no sentido de reduzir pontos fracos, consolidar pontos fortes, neutralizar ameaças e vislumbrar oportunidades. É um campo de diálogo que se processa nos mais diversos níveis de relacionamento, tanto interno quanto externo, ou seja, um espaço onde usuários do sistema de saúde podem se comunicar, além de os colaboradores também poderem se utilizar dessa ferramenta, portanto a característica de mero serviço ou cortesia adicional pode ser entendida e praticada como modalidade de interlocução. CUSSY (2011) aponta que as organizações já percebem a Ouvidoria como meio de estreitar o relacionamento com o cidadão, por uma via oficial e direta de comunicação, atuando com o objetivo de evitar perda de eficiência e responder de modo satisfatório como instrumento de política pública e participação social.

A garantia do direito à informação e a participação social são de fundamental importância em observância às lutas sociais, porém, além de ter esse direito garantido em uma Ouvidoria, torna-se imprescindível saber o que é feito com a informação, como o agente administrativo usa essa participação e como as informações chegam a influenciar as mudanças nos estabelecimentos públicos. Uma Ouvidoria Pública atua no diálogo entre o cidadão e a Administração Pública e as manifestações decorrem do exercício da cidadania, por isso a preocupação com a análise, coleta, classificação, manipulação, armazenamento, recuperação e disseminação da informação, ou seja, o processo de transformação de dados em conhecimento é de total importância para a contínua melhoria na prestação dos serviços.

A comunicação é uma atitude que deve estar presente na ocupação e na preocupação de todos os que compõem uma dada organização, pelo fato de esses serem representantes dessa organização perante seu público (IASBECK, 2006).

\section{REFERENCIAL TEÓRICO}

O Estado vem atravessando diversas mudanças, qualquer reflexão em torno da Administração Pública torna imprescindível a existência da participação e controle social em suas atividades. A sociedade e o agente público devem trabalhar em conjunto, com a finalidade de obter um resultado 
mais assertivo no gerenciamento dos recursos. A participação social e o gerenciamento dessas informações muitas vezes são observados sem que lhes seja atribuída real importância, ou seja, em alguns momentos percebemos que locais de participação popular são criados apenas para cumprir uma lei, não sendo dada a devida atenção às demandas e à população. Dessa forma, é importante saber como a participação popular e social influencia na gestão das Unidades de Pronto Atendimento - UPAs.

A Ouvidoria é um local onde o usuário pode exercer seus direitos de participar nas decisões da saúde pública, por isso é imprescindível saber qual o entendimento do gestor público sobre a participação social e, dessa forma, incentivar a ampliação da participação popular. O processo em uma Ouvidoria envolve pessoas, informação, atitude organizacional e exige a mediação para a construção do ser e do saber. Mediação deve ser entendida como uma técnica não adversa de resolução de conflitos, por meio da qual duas ou mais pessoas buscam auxílio de um indivíduo capacitado, neutro e especialmente treinado (BRAGA NETO, 1999).

A instalação de uma Ouvidoria traz a aproximação com os cidadãos, mediante uma comunicação acessível e direta, um relacionamento democrático com a sociedade, a identificação de necessidades dos usuários, entre outros. Muitas instituições públicas adotaram esse mecanismo como ponto de apoio no processo de modernização, buscando captar através de seus usuários o compartilhamento de suas ações com os anseios da sociedade, elevando o seu nível de eficiência e eficácia em meio à recuperação e consolidação da imagem do serviço público. As Ouvidorias Públicas são instrumento de cidadania e pilares fundamentais de sustentação da democracia moderna, devendo trabalhar pela satisfação dos cidadãos, atuando como promotoras e agentes de mudanças em prol de uma gestão pública democrática, transparente, participativa, ética, eficaz e eficiente.

IASBECK (2006), ao discutir Ouvidoria, considera que as pessoas que a ela recorrem são usuários, clientes, consumidores, cidadãos que possuem algum tipo de interesse nos negócios da organização. Esse usuário demonstra estar suficientemente motivado para acionar a organização e, por essa razão, mobiliza-se e oferece a ela diversificadas informações, desde as mais óbvias e explícitas, até outras que podem facilmente ser inferidas. Ao estabelecer como princípio organizativo do Sistema Único de Saúde (SUS) a participação comunitária, a Constituição Federal de 1988 apontou para a relevância da inserção da população brasileira na formulação de políticas públicas em defesa do direito à saúde. Além disso, atribuiu importância a instâncias populares na fiscalização e controle das ações do Estado, considerando as especificidades de cada região brasileira. A parceria entre sociedade civil e governos não apenas contribuiu para a consolidação da democracia como também possibilitou a construção de marcos históricos.

Sabemos que o fato de poder contar com as informações adequadas e oportunas são de grande importância para o sucesso de uma organização e, em consequência, do gestor. Uma Ouvidoria Pública atua no diálogo entre o cidadão e a Administração Pública, de modo que as manifestações decorrentes do exercício da cidadania provoquem contínua melhoria dos serviços públicos prestados. Para MAÑAS (2002), as informações e o conhecimento compõem recursos estratégicos essenciais para o sucesso de uma empresa. O conhecimento é o conteúdo comunicado na organização com real efeito para os participantes e edifica a aprendizagem organizacional (BULGACOV; MARCHIORI, 2008). Analisam-se as causas dessa problemática, partindo-se de um não funcio- 
namento reconhecido. De forma progressiva, é possível identificar inicialmente os problemas que são superficiais e, depois, os mais complexos. Essa colocação não é muito evidente na maioria dos estabelecimentos públicos e, para ser claramente entendida, é importante ter uma abordagem diferenciada. A informação transformou-se em recurso fundamental em qualquer organização. $O$ que se sente é que um número muito significativo dos responsáveis pelas atividades públicas não está preparado para tratar especificamente da informação como um recurso em si, e menos ainda para gerenciá-la, não a considerando como recurso estratégico. As Ouvidorias buscam afirmar a comunicação entre a sociedade e os órgãos públicos para ampliar a capilaridade e a efetividade das políticas públicas. Para tanto, é necessário divulgar o papel das Ouvidorias, disponibilizar o acesso a elas e imprimir celeridade às suas respostas, assim como exercitar/expor-se à participação, em esforço compartilhado entre Poder Público e sociedade civil.

\section{METODOLOGIA}

Com o intuito de identificar a importância de uma Ouvidoria dentro de uma unidade pública de saúde, foi utilizada a natureza qualitativa, que melhor se adequa às exigências metodológicas dessa pesquisa. Assim, a proposta metodológica norteadora foi o enfoque na pesquisa qualitativa exploratória.

Foram aplicadas entrevistas semiestruturadas com os gestores das Unidades de Pronto Atendimento. A pesquisa bibliográfica foi utilizada como fundamentação teórica do objeto de estudo mencionado, para contextualizar a temática a ser abordada e para estabelecer as referências de base teórica, a partir do contato com o que já foi produzido e registrado a respeito desse tema. $A$ pesquisa foi realizada nas UPAs, com agendamento prévio feito com os gestores para a realização da pesquisa.

\section{RESULTADOS E DISCUSSÃO}

As falas dos gestores foram analisadas e agrupadas em quatro categorias, a saber: 1) a visão do gestor sobre o trabalho da Ouvidoria; 2) a contribuição da Ouvidoria na melhoria das atividades de gestão; 3) a visão dos gestores sobre a importância da Ouvidoria como ferramenta de gestão participativa; e 4) a indicação da Ouvidoria como canal de participação social. Os entrevistados foram em sua maioria do sexo masculino, num total de 4 gestores e 3 gestoras, sendo 3 enfermeiras, 3 médicos e 1 odontólogo. 


\section{A visão do gestor sobre o trabalho da Ouvidoria}

1. Qual sua visão a respeito do trabalho de uma Ouvidoria Pública?

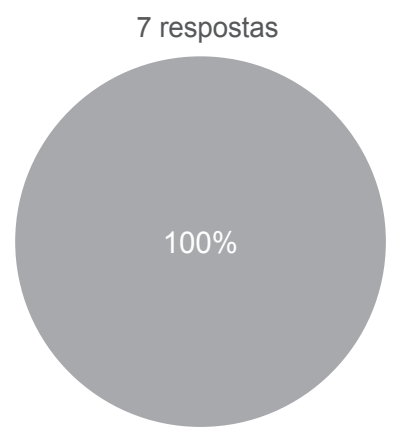

Contribui para o

conhecimento sobre

o desempenho dos

serviços oferecidos

à população.

Não contribui para a melhoria das atividades nas instituições.

Não conheço o

trabalho da Ouvidoria Pública.

Levando em consideração as três opções de resposta: contribui para o conhecimento sobre o desempenho dos serviços oferecidos à população; não contribui para a melhoria das atividades nas instituições; e não conhecem o trabalho da Ouvidoria Pública, 100\% dos gestores apontaram que a Ouvidoria contribui para o conhecimento sobre o desempenho das atividades, mostrando assim que as demandas coletadas pela Ouvidoria e encaminhadas à unidade servem como panorama das atividades, ao localizar, no serviço, os pontos positivos e pontos a melhorar.

\section{A contribuição da Ouvidoria na melhoria das atividades de gestão}

\section{O trabalho da Ouvidoria já contribui auxiliando-o na melhoria das atividades de gestão?}

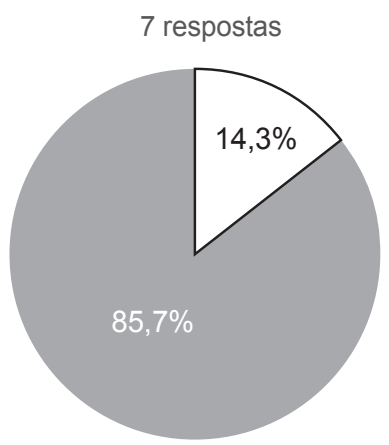

Todas as demandas encaminhadas pela Ouvidoria serviram para o aprimoramento dos nossos serviços.

Não contribui para a melhoria dos serviços.

Não conheço o trabalho da Ouvidoria Pública.

Algumas demandas serviram para o aprimoramento do serviço.

Nesse ponto, $86 \%$ dos gestores afirmaram que as demandas recebidas pela Ouvidoria e encaminhadas à gestão auxiliam na melhoria das atividades, mostrando assim a importância da partici- 
pação da população no serviço público, uma vez que o usuário é o maior interessado no produto do serviço ofertado. $14 \%$ dos gestores afirmaram que apenas algumas demandas contribuem para a melhoria das atividades de gestão.

\section{A visão dos gestores sobre a Ouvidoria como ferramenta de gestão participativa}

3. Na sua visão de gestor, a Ouvidoria é um instrumento de gestão participativa?

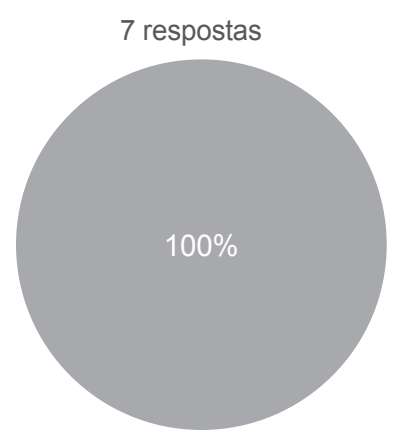

Sim, a Ouvidoria empodera o usuário dando a ele espaço para participar da gestão dos serviços públicos.

Acredito que a gestão do serviço público deve ser responsabilidade somente do gestor.

Não conheço o trabalho da Ouvidoria Pública.

Na resposta a essa pergunta, todos os gestores apontaram a Ouvidoria como uma ferramenta de gestão, atribuindo-Ihe uma importância estratégica para o gerenciamento das atividades.

\section{A indicação da Ouvidoria como canal de participação social}

4. Você indicaria a um usuário a utilização de um canal de Ouvidoria?

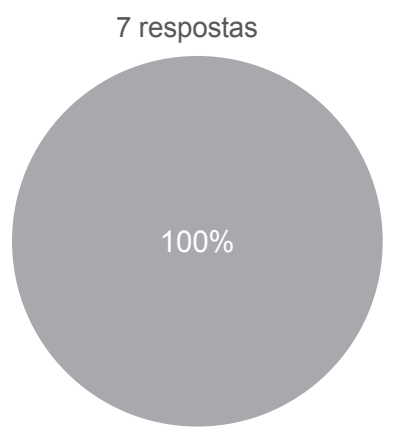

Sim, pois é um direito do usuário expressar sua visão sobre o serviço oferecido.

Não indico, acredito que não gera resultados para a gestão.

Não conheço o trabalho da Ouvidoria Pública.

Um total de $100 \%$ dos gestores afirmou que indicariam uma Ouvidoria como canal de participação dos usuários, portanto podemos considerar que eles levam em consideração a atuação da Ouvidoria e a participação social e dão importância a elas. 


\section{Tabela geral das respostas}

Demonstrativo de profissionais que alegaram eficiência total da Ouvidoria na Gestão Participativa

\begin{tabular}{|l|l|l|l|l|}
\hline Perguntas/ Profissionais & Médico (a) & Enfermeiro (a) & Odontólogo & Total \\
\hline $\begin{array}{l}\text { A visão do gestor sobre o trabalho } \\
\text { da Ouvidoria }\end{array}$ & 03 & 03 & 01 & $100 \%$ \\
\hline $\begin{array}{l}\text { A contribuição da Ouvidoria na } \\
\text { melhoria das atividades de gestão }\end{array}$ & 02 & 03 & 01 & $86 \%$ \\
\hline $\begin{array}{l}\text { Ouvidoria como ferramenta de } \\
\text { gestão participativa }\end{array}$ & 03 & 03 & 01 & $100 \%$ \\
\hline $\begin{array}{l}\text { A indicação da Ouvidoria como } \\
\text { canal de participação social }\end{array}$ & 03 & 03 & 01 & $100 \%$ \\
\hline
\end{tabular}

\section{CONCLUSÃO}

Conclui-se, portanto, que a Ouvidoria é um espaço onde o cidadão interage buscando alcançar seus objetivos, validando a qualidade do serviço ou contribuindo com a melhoria do serviço público.

Ficou evidenciado que, para os gestores das UPAs, a participação do cidadão através de suas manifestações contribui, auxiliando no gerenciamento e na tomada de decisão por parte da gestão, possibilitando analisar o serviço através da experiência do usuário do serviço, ou seja, para aquele cujo equipamento de saúde está destinado, o público-alvo.

Por fim, entendemos a Ouvidoria como canal ascendente de comunicação ao qual se faz necessário incentivar o uso, não só para garantir o direito do cidadão como um dos gestores do serviço público, mas também para a melhoria desses serviços.

\section{CONSIDERAÇÕES FINAIS}

Ao se adotar a concepção proposta, aprofunda-se a Ouvidoria como um espaço de gestão participativa, no qual o manifestante conversa a fim de alcançar seu objetivo, na espera de uma mudança, contribuindo, com saberes novos, para a organização. Considerando esse modelo e refletindo a Ouvidoria como canal ascendente de comunicação, é fundamental discuti-la como possibilidade real de incentivar relacionamentos com públicos e como processo necessariamente unido às pessoas.

Podemos concluir que a Ouvidoria das Unidades de Pronto Atendimento está estabelecida de forma clara e objetiva para os gestores. Eles apontam grande importância para o gerenciamento dos serviços, destacando a Ouvidoria como ferramenta de gestão. Ficou evidenciado que $86 \%$ dos gestores consideram que o setor de Ouvidoria contribui de forma significativa para a melhoria das atividades de gestão, pois traz ao conhecimento deles pontos com oportunidades de melhorias e pontos fortes que precisam ser preservados. 
Os gestores foram unânimes ao considerar a Ouvidoria uma ferramenta de gestão participativa, mostrando que existe o entendimento por parte da direção das unidades de que o cidadão é um participante ativo na gestão pública e que o canal de Ouvidoria amplia e facilita essa participação.

Por fim, observa-se a necessidade de estabelecer estratégias de divulgação e orientação para ampliar a participação dos usuários na utilização do serviço da Ouvidoria, já que se trata de uma política nacional e uma mudança de paradigma no atendimento público.

\section{REFERÊNCIAS}

A importância do Ouvidor para a sociedade. Disponível em: <http://www.administradores.com.br/artigos/negocios/a-importancia-da-ouvidoria-para-a-sociedade-2-publicacao/58261/>. Acesso em: 11 maio 2016.

A Ouvidoria como processo de construção de conhecimento. Disponível em: <http://www.uel.br/grupo-estudo/gecorp/ images/Capitulo_03_Ouvidoria.pdf>.

A política nacional de participação social. Disponível em: <http://www4.planalto.gov.br/arenadaparticipacaosocial/a-politica-nacional-de-participacao-social>. Acesso em: 17 maio 2016.

BLIKSTEIN, I.; ALVEZ, M. A.; GOMES, M. T. Nota técnica: os estudos organizacionais e a comunicação no Brasil. CLEGG, R.; HARDY, C.; NORD, W. (Org.). Handbook de estudos organizacionais. São Paulo: Atlas, 2009, p. 126130 , v. 3.

BULGACOV, S.; MARCHIORI, M. O ser e a comunicação dos saberes. In: MARCHIORI, M. (Org.). Faces da cultura e da comunicação organizacional. São Caetano do Sul: Difusão, 2008. p. 105-120.

BRASIL. Constituição (1988). Constituição da República Federativa do Brasil. Disponível em: <http://www.planalto. gov.br/ccivil_03/constituicao/constituicao.htm>. Acesso em: 02 fev. 2018.

Decreto n 8.243, de 23 de maio de 2014. Institui a Política Nacional de Participação Social - PNPS e o Sistema Nacional de Participação Social - SNPS, e dá outras providências. Disponível em: <http://www.planalto.gov. br/ccivil_03/_Ato2011-2014/2014/Decreto/D8243.htm>. Acesso em: 02 fev. 2018.

Ministério da Saúde/Derac. Regulação no setor saúde - em direção aos seus fundamentos públicos. Brasília: Ministério da Saúde, 2004.

CARDOSO, A. S. R. Ouvidoria X Mediação: Reflexões sobre um conflito. Julho 2006. Disponível em: <http://www.ipea.gov.br/ouvidoria/images/stories/pdf/artigo003.pdf>. Acesso em: 9 mai 2011.

CASSARO, A. C. Sistemas de Informação para a tomada de decisões. 3. ed. São Paulo: Pioneira Thomson, 2003.

FIGUEIREDO, Nice. Paul Otlet e o centenário da FID. In: Organização do conhecimento e sistemas de classificação. Brasília: IBICT, 1996.

IASBECK, L. C. A. Ouvidoria: Lugar Privilegiado de Comunicação Organizacional. 2006. Disponível em: <http:// galaxy. intercom.org.br:8180/dspace/bitstream/1904/20148/1/Luiz+Carlos+Assis+lasbeck.pdf>. Acesso em: $1^{\circ} \mathrm{maio}$ 2011.

MINAYO, Maria Cecília de Souza; SANCHES, O. Quantitativo-Qualitativo: oposição ou complementaridade? Cad. Saúde Pública, 93(3), p. 239-262, 1993.

MINISTÉRIO DA SAÚDE. Ouvidoria-geral: um espaço do SUS de cidadania. 2. ed., Brasília, 2014.

OTICS. Disponível em: <http://www.otics.org>. Acesso em: 26 dez. 2016.

OUVIDORIA. Disponível em: <http://www.cgu.gov.br/assuntos/ouvidoria>. Acesso em: 29 jan. 2018.

SARACEVIC, Tefko. Ciência da informação: origem, evolução e relações. Perspectivas em Ciência da Informação, Belo Horizonte, v. 1, n. 1, p. 4-62, jan./jun., 1996. 